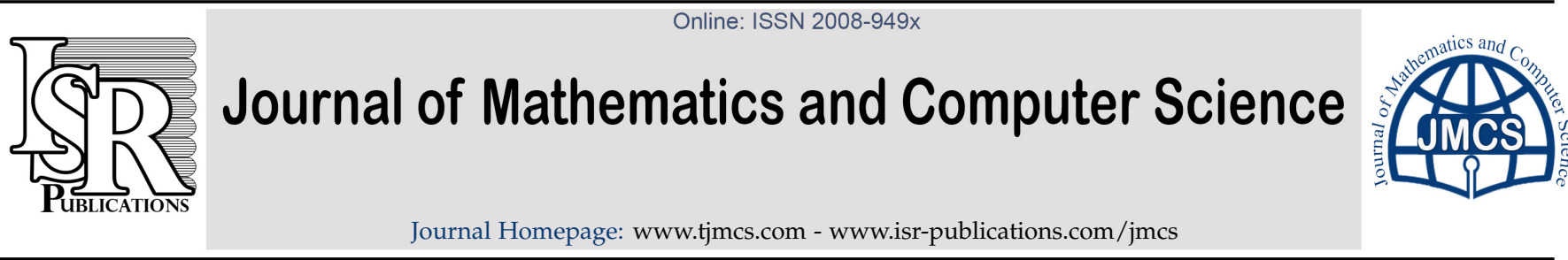

\title{
Asymptotic behavior of third-order neutral differential equations with distributed deviating arguments
}

\author{
Haixia Wang ${ }^{a, b}$, Guojuan Chen ${ }^{c}$, Ying Jiang ${ }^{b}$, Cuimei Jiang ${ }^{b}$, Tongxing Li $j^{c, d, *}$ \\ a School of Economics, Ocean University of China, Qingdao, Shandong 266100, P. R. China. \\ ${ }^{b}$ Qingdao Technological University, Feixian, Shandong 273400, P. R. China. \\ 'School of Informatics, Linyi University, Linyi, Shandong 276005, P. R. China. \\ ${ }^{d}$ LinDa Institute of Shandong Provincial Key Laboratory of Network Based Intelligent Computing, Linyi University, Linyi, Shandong \\ 276005, P. R. China.
}

\begin{abstract}
We consider the asymptotic behavior of solutions to a class of third-order neutral differential equations with distributed deviating arguments. Our criteria extend the related results reported in the literature. An illustrative example is included. (C)2017 all rights reserved.
\end{abstract}

Keywords: Asymptotic behavior, neutral differential equation, third-order, distributed deviating argument, oscillation. 2010 MSC: 34K11.

\section{Introduction}

Third-order differential equations arise in the study of entry-flow phenomenon, a problem of hydrodynamics, three-layer beams, and so forth; see the monograph [12] and papers [9, 15]. Analysis of the oscillation and asymptotic behavior of solutions to various classes of third-order differential equations always attracted interest of researchers; see, e.g., [1-11, 13-19, 22] and the references cited therein.

In this paper, we consider the asymptotic properties of solutions to a class of third-order neutral equations with distributed deviating arguments

$$
\left(a(t)\left[\left(b(t)[x(t)+p(t) x(\sigma(t))]^{\prime}\right)^{\prime}\right]^{\alpha}\right)^{\prime}+\int_{c}^{d} q(t, \xi) f(x(\tau(t, \xi))) d \xi=0,
$$

where $t \geqslant t_{0}$ and $\alpha>0$ is a ratio of two odd positive integers. Throughout this paper, we assume that the following hypotheses hold:

$$
\begin{array}{ll}
\left(H_{1}\right) & a(t), b(t), p(t) \in C\left(\left[t_{0}, \infty\right), \mathbb{R}\right), a(t)>0, b(t)>0,0 \leqslant p(t) \leqslant p_{0}<1, \int_{t_{0}}^{\infty} a^{-1 / \alpha}(t) d t=\infty, \\
& \int_{t_{0}}^{\infty}(b(t))^{-1} d t=\infty, q(t, \xi) \in C\left(\left[t_{0}, \infty\right) \times[c, d],[0, \infty)\right), \text { and } q(t, \xi) \text { is not identically zero for large } \\
& t ;
\end{array}
$$

\footnotetext{
*Corresponding author

Email address: litongx2007@163.com (Tongxing Li)
}

doi:10.22436/jmcs.017.02.01 
$\left(\mathrm{H}_{2}\right) \sigma(\mathrm{t}) \in \mathrm{C}\left(\left[\mathrm{t}_{0}, \infty\right), \mathbb{R}\right), \sigma(\mathrm{t}) \leqslant \mathrm{t}, \lim _{\mathrm{t} \rightarrow \infty} \sigma(\mathrm{t})=\infty, \tau(\mathrm{t}, \xi) \in \mathrm{C}\left(\left[\mathrm{t}_{0}, \infty\right) \times[\mathrm{c}, \mathrm{d}], \mathbb{R}\right)$ is a nondecreasing function for $\xi$ satisfying $\tau(t, \xi) \leqslant t$, and $\liminf _{t \rightarrow \infty} \tau(t, \xi)=\infty$ for $\xi \in[c, d]$;

$\left(\mathrm{H}_{3}\right) \mathrm{f} \in \mathrm{C}(\mathbb{R}, \mathbb{R})$ and there exists a positive constant $k$ such that $f(u) / u^{\alpha} \geqslant k$ for all $u \neq 0$.

Let

$$
z(t):=x(t)+p(t) x(\sigma(t))
$$

By a solution to (1.1) we mean a nontrivial function $x(t) \in C\left(\left[t_{x}, \infty\right), \mathbb{R}\right), t_{x} \geqslant t_{0}$, such that $z(t) \in$ $C^{1}\left(\left[t_{x}, \infty\right), \mathbb{R}\right), b(t) z^{\prime}(t) \in C^{1}\left(\left[t_{x}, \infty\right), \mathbb{R}\right), a(t)\left[\left(b(t) z^{\prime}(t)\right)^{\prime}\right]^{\alpha} \in C^{1}\left(\left[t_{x}, \infty\right), \mathbb{R}\right)$ and $x(t)$ satisfies (1.1) on the interval $\left[t_{x}, \infty\right)$. The solutions vanishing in some neighborhood of infinity will be excluded from our consideration. A solution of (1.1) is said to be oscillatory if it is neither eventually positive nor eventually negative; otherwise, it is termed nonoscillatory.

In what follows, we present some background details that motivate the contents of this paper. Agarwal et al. [1-4] and Li and Rogovchenko [17] studied the asymptotic behavior of a third-order delay differential equation

$$
\left(a(t)\left(x^{\prime \prime}(t)\right)^{\alpha}\right)^{\prime}+q(t) f(x(\tau(t)))=0 .
$$

Baculíková and Džurina [5], Jiang et al. [14], Jiang and Li [15], and Li and Zhang [18] considered the asymptotic properties of a class of third-order neutral differential equations

$$
\left(a(t)\left([x(t)+p(t) x(\sigma(t))]^{\prime \prime}\right)^{\alpha}\right)^{\prime}+q(t) x^{\alpha}(\tau(t))=0,
$$

whereas Došlá and Liška [9] and Li et al. [19] investigated a general third-order neutral differential equation

$$
\left(\mathrm{a}(\mathrm{t})\left(\mathrm{b}(\mathrm{t})[\mathrm{x}(\mathrm{t})+\mathrm{p}(\mathrm{t}) x(\sigma(\mathrm{t}))]^{\prime}\right)^{\prime}\right)^{\prime}+\mathrm{q}(\mathrm{t}) x(\tau(\mathrm{t}))=0 .
$$

Bohner et al. [6, 7] and Džurina and Kotorová [10] studied the oscillatory behavior of a third-order delay differential equation with damping

$$
x^{\prime \prime \prime}(t)+p(t) x^{\prime}(t)+q(t) f(x(\tau(t)))=0,
$$

whereas Li and Rogovchenko [16] considered a third-order delay differential equation

$$
x^{\prime \prime \prime}(\mathrm{t})+\mathrm{p}(\mathrm{t}) x^{\prime \prime}(\mathrm{t})+\mathrm{q}(\mathrm{t}) \mathrm{f}(\mathrm{x}(\tau(\mathrm{t})))=0
$$

Candan [8], Fu et al. [11], Jiang et al. [13], Şenel and Utku [20, 21], and Tian et al. [22] established several criteria for the oscillation and asymptotic behavior of a third-order neutral differential equation with distributed deviating arguments

$$
\left(a(t)\left([x(t)+p(t) x(\sigma(t))]^{\prime \prime}\right)^{\alpha}\right)^{\prime}+\int_{c}^{d} q(t, \xi) f(x(\tau(t, \xi))) d \xi=0 .
$$

Assuming that $u(t)$ is a positive solution of the equation $u^{\prime \prime}(t)+p(t) u(t)=0$, it is not difficult to see that equations

$$
x^{\prime \prime \prime}(t)+p(t) x^{\prime}(t)+\int_{c}^{d} q(t, \xi) f(x(\tau(t, \xi))) d \xi=0
$$

and

$$
\left(u^{2}(t)\left(\frac{1}{u(t)} x^{\prime}(t)\right)^{\prime}\right)^{\prime}+u(t) \int_{c}^{d} q(t, \xi) f(x(\tau(t, \xi))) d \xi=0
$$

are equivalent, and hence it is interesting to study equation (1.1).

In the sequel, all functional inequalities are assumed to hold eventually. 


\section{Auxiliary lemmas}

To prove our main results, we need the following useful lemmas.

Lemma 2.1. Let conditions $\left(\mathrm{H}_{1}\right)-\left(\mathrm{H}_{3}\right)$ be satisfied and suppose that $\mathrm{x}(\mathrm{t})$ is an eventually positive solution of (1.1). Then there are only the following two possible cases for $z(t)$ :

(I) $z(\mathrm{t})>0, z^{\prime}(\mathrm{t})>0,\left(\mathrm{~b}(\mathrm{t}) z^{\prime}(\mathrm{t})\right)^{\prime}>0$, and $\left(\mathrm{a}(\mathrm{t})\left[\left(\mathrm{b}(\mathrm{t}) z^{\prime}(\mathrm{t})\right)^{\prime}\right]^{\alpha}\right)^{\prime} \leqslant 0$;

(II) $z(\mathrm{t})>0, z^{\prime}(\mathrm{t})<0,\left(\mathrm{~b}(\mathrm{t}) z^{\prime}(\mathrm{t})\right)^{\prime}>0$, and $\left(\mathrm{a}(\mathrm{t})\left[\left(\mathrm{b}(\mathrm{t}) \mathrm{z}^{\prime}(\mathrm{t})\right)^{\prime}\right]^{\alpha}\right)^{\prime} \leqslant 0$,

for $\mathrm{t} \geqslant \mathrm{t}_{1}$, where $\mathrm{t}_{1} \geqslant \mathrm{t}_{0}$ is sufficiently large.

Proof. The proof is simple, and so is omitted.

Lemma 2.2. Let $x(t)$ be an eventually positive solution of (1.1). If $z(t)$ satisfies case (I) in Lemma 2.1, then for all sufficiently large $t_{1} \geqslant t_{0}$ there exists a $t_{2}>t_{1}$ such that, for $t \geqslant t_{2}$,

$$
\frac{z(t)}{b(t) z^{\prime}(t)} \geqslant \frac{\int_{t_{2}}^{t} \frac{\int_{t_{1}}^{s} a^{-1 / \alpha}(u) d u}{b(s)} d s}{\int_{t_{1}}^{t} a^{-1 / \alpha}(u) d u}
$$

and $\mathrm{b}(\mathrm{t}) \mathrm{z}^{\prime}(\mathrm{t}) / \int_{\mathrm{t}_{1}}^{\mathrm{t}} \mathrm{a}^{-1 / \alpha}(\mathrm{u}) \mathrm{du}$ is nonincreasing eventually.

Proof. The proof is similar to that of [13, Lemma 2.2], and hence is omitted.

Lemma 2.3. Let $x(t)$ be an eventually positive solution of (1.1) and assume that $z(t)$ satisfies case (II) in Lemma 2.1. If

$$
\int_{\mathfrak{t}_{0}}^{\infty} \frac{1}{\mathrm{~b}(v)} \int_{v}^{\infty}\left(\frac{1}{\mathrm{a}(u)} \int_{\mathfrak{u}}^{\infty} \int_{c}^{\mathrm{d}} \mathrm{q}(s, \xi) \mathrm{d} \xi \mathrm{d} s\right)^{1 / \alpha} \mathrm{d} u \mathrm{~d} v=\infty,
$$

then $\lim _{t \rightarrow \infty} x(t)=0$.

Proof. The proof is similar to that of [5, Lemma 2], and therefore is omitted.

\section{Main results}

For simplicity, we introduce the following notation:

$$
\begin{aligned}
& \mathrm{q}_{1}(\mathrm{t}):=\mathrm{k}\left(1-\mathrm{p}_{0}\right)^{\alpha} \int_{c}^{\mathrm{d}} \mathrm{q}(\mathrm{t}, \xi) \mathrm{d} \xi, \quad \tau_{1}(\mathrm{t}):=\tau(\mathrm{t}, \mathrm{c}), \\
& \rho_{+}^{\prime}(\mathrm{t}):=\max \left\{0, \rho^{\prime}(\mathrm{t})\right\}, \quad \text { and } \quad \mathrm{G}(\mathrm{t}):=\rho(\mathrm{t}) \mathrm{q}_{1}(\mathrm{t})\left(\frac{\int_{\mathrm{t}_{2}}^{\tau_{1}(t)}\left(\int_{\mathrm{t}_{1}}^{s} a^{-1 / \alpha}(u) d u / b(s)\right) d s}{\int_{t_{1}}^{t} a^{-1 / \alpha}(u) d u}\right)^{\alpha},
\end{aligned}
$$

where the meaning of $\rho(t)$ will be explained later.

Theorem 3.1. Assume that conditions $\left(\mathrm{H}_{1}\right)-\left(\mathrm{H}_{3}\right)$ and (2.1) hold. If there exists a function $\rho(\mathrm{t}) \in \mathrm{C}^{1}\left(\left(\mathrm{t}_{0}, \infty\right),(0, \infty)\right)$ such that, for all sufficiently large $t_{1} \geqslant t_{0}$ and for some $t_{3}>t_{2}>t_{1}$,

$$
\limsup _{t \rightarrow \infty} \int_{t_{3}}^{t}\left(G(s)-\frac{1}{(\alpha+1)^{1+\alpha}} \frac{a(s)\left(\rho_{+}^{\prime}(s)\right)^{1+\alpha}}{\rho^{\alpha}(s)}\right) d s=\infty,
$$

then every solution $x(t)$ of (1.1) is either oscillatory or satisfies $\lim _{t \rightarrow \infty} x(t)=0$. 
Proof. Let $x(t)$ be a nonoscillatory solution of (1.1). Without loss of generality, we may assume that $x(t)$ is eventually positive. By Lemma 2.1, $z(t)$ satisfies either case (I) or case (II).

Assume first that case (I) holds for $t \geqslant t_{1}$. By virtue of the definition of $z(t)$,

$$
x(t)=z(t)-p(t) x(\sigma(t)) \geqslant z(t)-p(t) z(\sigma(t)) \geqslant\left(1-p_{0}\right) z(t) .
$$

It follows from (1.1) and (3.2) that

$$
\begin{aligned}
\left(a(t)\left[\left(b(t) z^{\prime}(t)\right)^{\prime}\right]^{\alpha}\right)^{\prime} & \leqslant-k \int_{c}^{d} q(t, \xi) x^{\alpha}(\tau(t, \xi)) d \xi \\
& \leqslant-k\left(1-p_{0}\right)^{\alpha} \int_{c}^{d} q(t, \xi) z^{\alpha}(\tau(t, \xi)) d \xi \\
& \leqslant-k\left(1-p_{0}\right)^{\alpha} z^{\alpha}(\tau(t, c)) \int_{c}^{d} q(t, \xi) d \xi \\
& =-q_{1}(t) z^{\alpha}\left(\tau_{1}(t)\right) .
\end{aligned}
$$

Define a new function $\omega(t)$ by

$$
\omega(t):=\rho(t) \frac{a(t)\left[\left(b(t) z^{\prime}(t)\right)^{\prime}\right]^{\alpha}}{\left[b(t) z^{\prime}(t)\right]^{\alpha}}
$$

Then $\omega(t)>0$ and

$$
\omega^{\prime}(t)=\frac{\rho^{\prime}(t)}{\rho(t)} \omega(t)+\rho(t) \frac{\left(a(t)\left[\left(b(t) z^{\prime}(t)\right)^{\prime}\right]^{\alpha}\right)^{\prime}}{\left[b(t) z^{\prime}(t)\right]^{\alpha}}-\alpha \rho(t) a(t) \frac{\left[\left(b(t) z^{\prime}(t)\right)^{\prime}\right]^{\alpha+1}}{\left[b(t) z^{\prime}(t)\right]^{\alpha+1}} .
$$

By (3.4), we get

$$
\left(\frac{\left(b(t) z^{\prime}(t)\right)^{\prime}}{b(t) z^{\prime}(t)}\right)^{\alpha+1}=\left(\frac{\omega(t)}{\rho(t) a(t)}\right)^{(\alpha+1) / \alpha} .
$$

Substituting (3.3) and (3.6) into (3.5), we conclude that

$$
\begin{aligned}
\omega^{\prime}(t) & \leqslant \frac{\rho^{\prime}(t)}{\rho(t)} \omega(t)-\rho(t) q_{1}(t) \frac{z^{\alpha}\left(\tau_{1}(t)\right)}{\left[b(t) z^{\prime}(t)\right]^{\alpha}}-\alpha \frac{\omega^{(\alpha+1) / \alpha}(t)}{(\rho(t) a(t))^{1 / \alpha}} \\
& =\frac{\rho^{\prime}(t)}{\rho(t)} \omega(t)-\rho(t) q_{1}(t)\left(\frac{z\left(\tau_{1}(t)\right)}{b\left(\tau_{1}(t)\right) z^{\prime}\left(\tau_{1}(t)\right)} \frac{b\left(\tau_{1}(t)\right) z^{\prime}\left(\tau_{1}(t)\right)}{b(t) z^{\prime}(t)}\right)^{\alpha}-\alpha \frac{\omega^{(\alpha+1) / \alpha}(t)}{(\rho(t) a(t))^{1 / \alpha}} .
\end{aligned}
$$

By virtue of Lemma 2.2, there exists a $t_{2}>t_{1}$ such that, for $t \geqslant t_{2}$,

$$
\frac{z\left(\tau_{1}(t)\right)}{b\left(\tau_{1}(t)\right) z^{\prime}\left(\tau_{1}(t)\right)} \geqslant \frac{\int_{t_{2}}^{\tau_{1}(t)}\left(\int_{t_{1}}^{s} a^{-1 / \alpha}(u) d u / b(s)\right) d s}{\int_{t_{1}}^{\tau_{1}(t)} a^{-1 / \alpha}(u) d u}
$$

and

$$
\frac{b\left(\tau_{1}(t)\right) z^{\prime}\left(\tau_{1}(t)\right)}{b(t) z^{\prime}(t)} \geqslant \frac{\int_{t_{1}}^{\tau_{1}(t)} a^{-1 / \alpha}(u) d u}{\int_{t_{1}}^{t} a^{-1 / \alpha}(u) d u}
$$

It follows now from (3.7) and the latter inequalities that

$$
\omega^{\prime}(t) \leqslant \frac{\rho_{+}^{\prime}(t)}{\rho(t)} \omega(t)-\rho(t) q_{1}(t)\left(\frac{\int_{t_{2}}^{\tau_{1}(t)}\left(\int_{t_{1}}^{s} a^{-1 / \alpha}(u) d u / b(s)\right) d s}{\int_{t_{1}}^{t} a^{-1 / \alpha}(u) d u}\right)^{\alpha}-\alpha \frac{\omega^{(\alpha+1) / \alpha}(t)}{(\rho(t) a(t))^{1 / \alpha}} .
$$

Let

$$
y:=\omega(t), \quad A:=\frac{\alpha}{(\rho(t) a(t))^{1 / \alpha}}, \quad \text { and } \quad B:=\frac{\rho_{+}^{\prime}(t)}{\rho(t)}
$$


Using the inequality (see [16])

$$
B y-A y^{(\alpha+1) / \alpha} \leqslant \frac{\alpha^{\alpha}}{(\alpha+1)^{\alpha+1}} \frac{B^{1+\alpha}}{A^{\alpha}}, \quad A>0,
$$

we have

$$
\frac{\rho_{+}^{\prime}(t)}{\rho(t)} \omega(t)-\alpha \frac{\omega^{(\alpha+1) / \alpha}(t)}{(\rho(t) a(t))^{1 / \alpha}} \leqslant \frac{1}{(\alpha+1)^{1+\alpha}} \frac{a(t)\left(\rho_{+}^{\prime}(t)\right)^{1+\alpha}}{\rho^{\alpha}(t)} .
$$

By (3.8), we deduce that

$$
\omega^{\prime}(t) \leqslant-G(t)+\frac{1}{(\alpha+1)^{1+\alpha}} \frac{a(t)\left(\rho_{+}^{\prime}(t)\right)^{1+\alpha}}{\rho^{\alpha}(t)} .
$$

Hence, there exists a $t_{3}>t_{2}$ such that

$$
\int_{t_{3}}^{t}\left(G(s)-\frac{1}{(\alpha+1)^{1+\alpha}} \frac{a(s)\left(\rho_{+}^{\prime}(s)\right)^{1+\alpha}}{\rho^{\alpha}(s)}\right) d s \leqslant \omega\left(t_{3}\right),
$$

which contradicts (3.1).

Assume now that case (II) holds for $t \geqslant t_{1}$. It follows from Lemma 2.3 that $\lim _{t \rightarrow \infty} x(t)=0$. This completes the proof.

Remark 3.2. One can derive from Theorem 3.1 a number of asymptotic criteria for (1.1) with an appropriate choice of $\rho(t)$. For example, we have the following result by letting $\rho(t)=1$.

Corollary 3.3. Let conditions $\left(\mathrm{H}_{1}\right)-\left(\mathrm{H}_{3}\right)$ and (2.1) be satisfied. If for all sufficiently large $\mathrm{t}_{1} \geqslant \mathrm{t}_{0}$ and for some $t_{3}>t_{2}>t_{1}$

$$
\int_{t_{3}}^{\infty} G(t) d t=\infty
$$

then the conclusion of Theorem 3.1 remains intact.

Remark 3.4. Theorem 3.1 extends [19, Theorem 2.1].

We provide the following example to illustrate the main results.

Example 3.5. For $t \geqslant 1$, consider a third-order neutral differential equation

$$
\left[e^{-t}\left(x(t)+e^{-\pi} x(t-\pi)\right)^{\prime}\right]^{\prime \prime}+\left(1-e^{-2 \pi}\right) \int_{-5 \pi / 2}^{-\pi} e^{-t-\xi} x(t+\xi) d \xi=0 .
$$

Let $\rho(t)=t$. It is not difficult to verify that all assumptions of Theorem 3.1 are satisfied. Therefore, every solution $x(t)$ of (3.9) is either oscillatory or satisfies $\lim _{t \rightarrow \infty} x(t)=0$. In fact, $x(t)=e^{t} \sin t$ is an oscillatory solution to this equation.

\section{Acknowledgment}

This research is supported by NNSF of P. R. China (Grant Nos. 61503171, 61403061, and 11447005), CPSF (Grant No. 2015M582091), NSF of Shandong Province (Grant No. ZR2016JL021), DSRF of Linyi University (Grant No. LYDX2015BS001), and the AMEP of Linyi University, P. R. China.

\section{References}

[1] R. P. Agarwal, M. Bohner, T.-X. Li, C.-H. Zhang, Hille and Nehari type criteria for third-order delay dynamic equations, J. Difference Equ. Appl., 19 (2013), 1563-1579. 1, 1

[2] R. P. Agarwal, M. Bohner, T.-X. Li, C.-H. Zhang, Oscillation of third-order nonlinear delay differential equations, Taiwanese J. Math., 17 (2013), 545-558. 
[3] R. P. Agarwal, M. Bohner, T.-X. Li, C.-H. Zhang, A Philos-type theorem for third-order nonlinear retarded dynamic equations, Appl. Math. Comput., 249 (2014), 527-531.

[4] R. P. Agarwal, M. Bohner, S.-H. Tang, T.-X. Li, C.-H. Zhang, Oscillation and asymptotic behavior of third-order nonlinear retarded dynamic equations, Appl. Math. Comput., 219 (2012), 3600-3609. 1

[5] B. Baculíková, J. Džurina, Oscillation of third-order neutral differential equations, Math. Comput. Modelling, 52 (2010), 215-226. 1, 2

[6] M. Bohner, S. R. Grace, I. Jadlovská, Oscillation criteria for third-order functional differential equations with damping, Electron. J. Differential Equations, 2016 (2016), 15 pages. 1

[7] M. Bohner, S. R. Grace, I. Sağer, E. Tunç, Oscillation of third-order nonlinear damped delay differential equations, Appl. Math. Comput., 278 (2016), 21-32. 1

[8] T. Candan, Oscillation criteria and asymptotic properties of solutions of third-order nonlinear neutral differential equations, Math. Methods Appl. Sci., 38 (2015), 1379-1392. 1

[9] Z. Došlá, P. Liška, Oscillation of third-order nonlinear neutral differential equations, Appl. Math. Lett., 56 (2016), $42-48$. 1,1

[10] J. Džurina, R. Kotorová, Properties of the third order trinomial differential equations with delay argument, Nonlinear Anal., 71 (2009), 1995-2002. 1

[11] Y.-L. Fu, Y.-Z. Tian, C.-M. Jiang, T.-X. Li, On the asymptotic properties of nonlinear third-order neutral delay differential equations with distributed deviating arguments, J. Funct. Spaces, 2016 (2016), 5 pages. 1, 1

[12] J. K. Hale. Theory of functional differential equations, Second edition. Applied Mathematical Sciences, SpringerVerlag, New York-Heidelberg, (1977). 1

[13] C.-M. Jiang, Y. Jiang, T.-X. Li, Asymptotic behavior of third-order differential equations with nonpositive neutral coefficients and distributed deviating arguments, Adv. Difference Equ., 2016 (2016), 14 pages. 1, 1, 2

[14] Y. Jiang, C.-M. Jiang, T.-X. Li, Oscillatory behavior of third-order nonlinear neutral delay differential equations, Adv. Difference Equ., 2016 (2016), 12 pages. 1

[15] Y. Jiang, T.-X. Li, Asymptotic behavior of a third-order nonlinear neutral delay differential equation, J. Inequal. Appl., 2014 (2014), 7 pages. 1, 1

[16] T.-X. Li, Y. V. Rogovchenko, Asymptotic behavior of an odd-order delay differential equation, Bound. Value Probl., 2014 (2014), 10 pages. 1, 3

[17] T.-X. Li, Y. V. Rogovchenko, Asymptotic behavior of higher-order quasilinear neutral differential equations, Abstr. Appl. Anal., 2014 (2014), 11 pages. 1

[18] T.-X. Li, C.-H. Zhang, Properties of third-order half-linear dynamic equations with an unbounded neutral coefficient, Adv. Difference Equ., 2013 (2013), 8 pages. 1

[19] T.-X. Li, C.-H. Zhang, G.-J. Xing, Oscillation of third-order neutral delay differential equations, Abstr. Appl. Anal., 2012 (2012), 11 pages. $1,1,3.4$

[20] M. T. Şenel, N. Utku, Oscillation behavior of third-order nonlinear neutral dynamic equations on time scales with distributed deviating arguments, Filomat, 28 (2014), 1211-1223. 1

[21] M. T. Şenel, N. Utku, Oscillation criteria for third-order neutral dynamic equations with continuously distributed delay, Adv. Difference Equ., 2014 (2014), 15 pages. 1

[22] Y.-Z. Tian, Y.-L. Cai, Y.-L. Fu, T.-X. Li, Oscillation and asymptotic behavior of third-order neutral differential equations with distributed deviating arguments, Adv. Difference Equ., 2015 (2015), 14 pages. 1, 1 